\title{
A growing wave of change in the food industry
}

Keywords: food industry, new wave of change, food safety, quality management, food and health protection

Abbreviations: TQM, total quality management; SWOT, strength weakness opportunity threat analysis; SPC, statistical process control; SQC, statistical quality control; GFSI, global food safety initiative; HACCP, hazard analysis and critical control Point; ISO, international standards organization; SSQA, safety, security and quality assurance

\section{Opinion}

The food industry may be facing a new wave of change (Figure $1)$. With expanding demands from enlightened consumers who are getting more and more connected via social media, the industry must adapt to better protect them and satisfy their expectations. An inevitable part of consumer protection is the effective management of food safety and quality assurance systems.

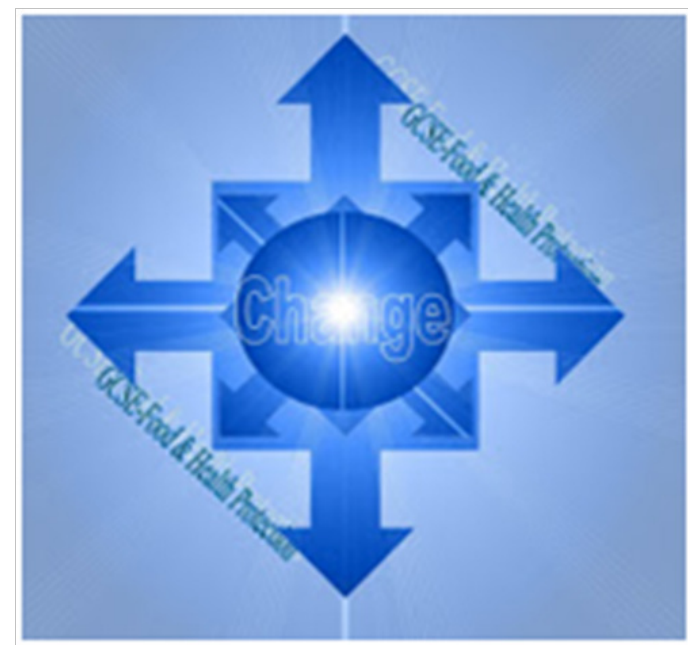

Figure I New wave of change.

Various concepts for product safety and quality management have evolved over the years. ${ }^{1}$ Management systems have progressed from periods of complete absence of formal approaches to the adoption of various models. Some examples include: Total Quality Management (TQM); Six Sigma and the 5-S or 6-S systems (Sorting, Stabilizing or Straightening, Sweeping or Shining, Standardizing, Sustaining the Practice); Strength, Weakness, Opportunity, Threat analysis (SWOT); Failure Mode and Effects Analysis (FMEA); Statistical Process Control, Statistical Quality Control (SPC/SQC); and more. There are Lean Manufacturing approaches, ISO (International Standards Organization) systems, the Hazard Analysis and Critical Control Point (HACCP) systems, Global Food Safety Initiative (GFSI) benchmarking, et cetera. The evolution continues with the Safety, Security and Quality Assurance (SSQA) concept.

The call for meaningful change has long been made by the Global
Volume 7 Issue I - 2017

\section{Felix Amiri}

Felix Amiri, Food Safety and Quality Systems Consultant at Amiri Food Industry Support Services (AFISS) and Instructor at the Institute of Food Processing Technology (IFPT), Canada

\author{
Correspondence: Felix Amiri, Food Safety and Quality \\ Systems Consultant at Amiri Food Industry Support Services \\ (AFISS) and Instructor at the Institute of Food Processing \\ Technology (IFPT), 77I Waterloo Street, Mount Forest, Ontario, \\ NOG 2L3, Canada, Tel (5I9) 26I0044, \\ Email felix@afisservices.com
}

Received: June 26, 2017 | Published: August 10, 2017

Coalition for Sustained Excellence in Food and Health Protection. In one of the Coalitions blogs posts, "The Coming Shift" some predictions were made that are already being experienced. For example, incidents of recalls are continuing unabated in spite of expanding certifications. This has been one of the predictions.

Superficiality and unwarranted reliance on food safety certification is continuing to expand. Many of the food safety certification assessment programs focus on taking "spectacular" snap shots (the socalled snap shot audits) based on generic standards. With an excessive focus on these generic standards, auditors often fail to notice actual realities at audited sites that lead to food safety failures. This will change and may already be changing. For example, in announcing the acquisition of BRC Global Standards by LGC, Mark Proctor, ${ }^{2}$ BRC Chief Executive Officer stated: "I wanted to personally let you know that BRC Global Standards is in the midst of an exciting strategic transition from being a Standards owner to a brand and consumer protection organisation with a range of products and services to help its customers deal with the challenges of producing safe, high quality products for the end consumer on a global basis" (Figure 2).
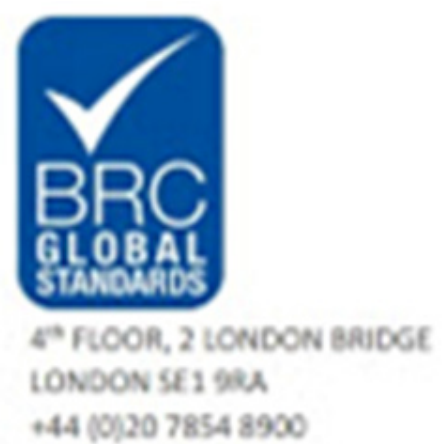

$+44(0), 2078548900$

http:ilwww.breglobalstandards.com/Hoen. aspx

Figure 2 BRC global standards. 
Perhaps BRC (British Retail Consortium) and LGC have recognized the superficiality of food safety certification schemes (often styled as "standards") and are moving away from them. The same switch is recommended for other parties that remain captivated by the certification idea. The pursuit of certification does no more than hold food businesses captive to a false sense of food safety security.

The food industry needs real solutions. Food businesses need to be practically and productively assisted instead of being subjected to certification audits that do more harm than good. The certification enterprise encumbers more than it inspires operators. One wonders if LGC and BRC have been listening to the call by GCSE-Food \& Health Protection. This might have led them to this announcement of a "strategic transition from being a Standards owner to a brand and consumer protection organisation".

The desire to move away from superficial certification of food safety and quality management systems appears to be growing. ${ }^{3}$ The reported new regulatory direction proposed by the EU and ${ }^{4}$ UK-FSA (Figure 3), the ${ }^{5}$ SQFI data reporting attempt (although it is a failed attempt) at reporting on the effectiveness of the SQF program, and the announcement about BRC transition under LGC ownership, all show evidence of a shift that may be happening underground. These pronouncements and attempts are encouraging but the battle is not over. The recognition is spreading but action within the industry is stagnant. Amidst loud claims of success, a reality-check shows that the industry needs more than superficial change: It needs a paradigm shift.

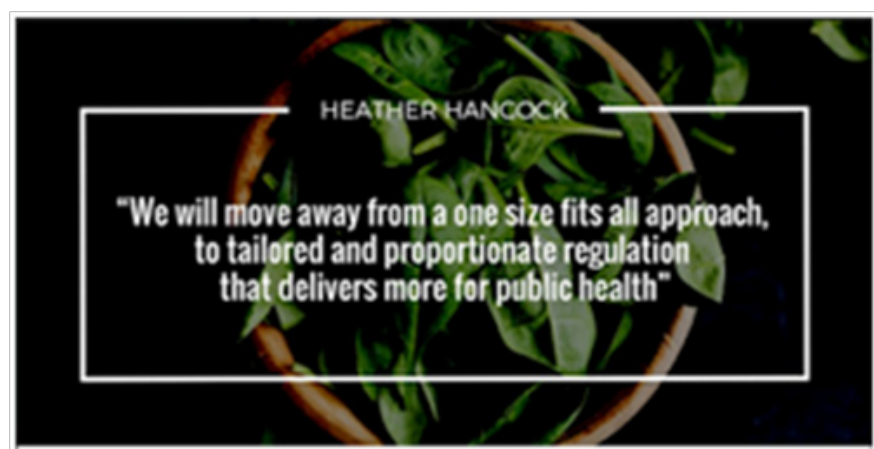

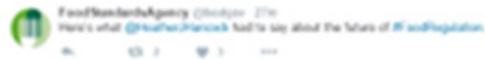

Figure 3 Food standard agencies.

It should not continue to pursue wasteful certification activities that create a finger-crossing environment where vigilance is relaxed as soon as the auditor is gone. A false sense of security may be celebrated on the basis of acquired documentation, but trouble awaits those who relax after certification (Figure 4).

Certificates provide no shield when problems occur. Food businesses need the anchor of consistent fortification through practical collaboration as promoted under the SSQA concept. A "crossedfingers" approach to food safety and quality management has no potency whatsoever (Figure 4).

The campaign against superficiality, misdirection, wasted resources and failing efforts at ensuring the safety of food must continue. All parties involved in the assurance of food/consumer safety need to drop the "certification" idea and focus on the SSQAstyle of fortification (Figure 5).

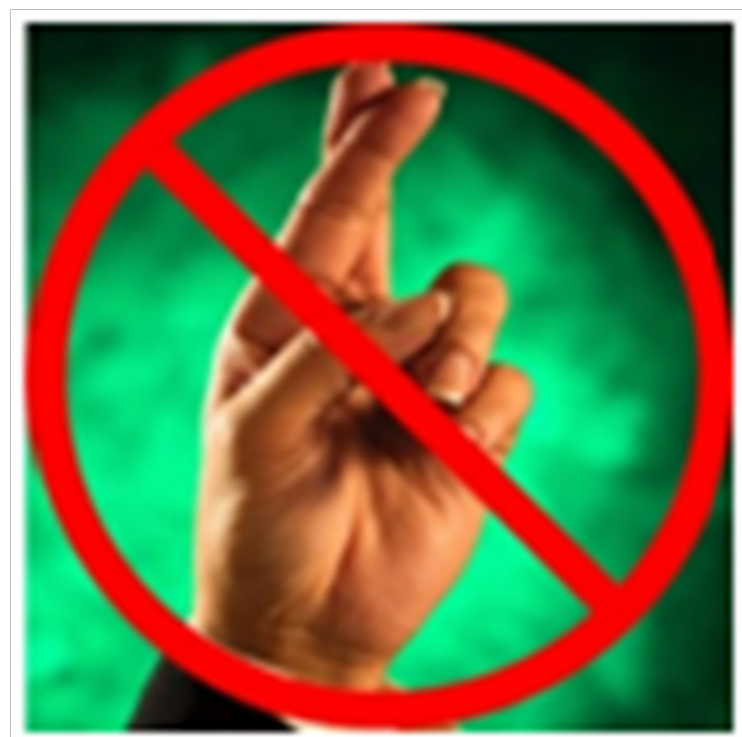

Figure $4 \mathrm{~A}$ "crossed-fingers" approach to food safety and quality management has no potency whatsoever.

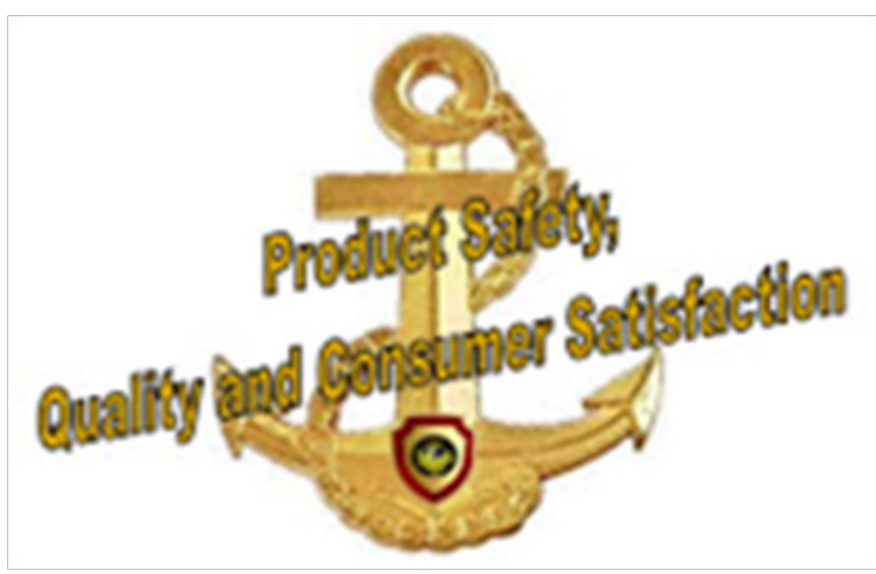

Figure 5 SSQA concept.

\section{Acknowledgements}

None.

\section{Conflict of interest}

Author declares that there is no conflict of interest.

\section{References}

1. Amiri F. Adopting the GCSE-Food \& Health Protection SSQA - Safety. Security and Quality Assurance Model. 2012

2. LGC acquires BRC Global Standards. BRC Global Standards. Press Release. 2016.

3. Food and Feed Safety. European Commission DG Health and Food Safety. 2016.

4. Regulating Our Future. Food Standards Agency. 2017.

5. Chuboff L. SQF 2016 and Beyond. International conference. 2016. 